\title{
MANAJEMEN PELATIHAN MASTERING ISLAMIC FINANCE DI PUSDIKLAT KEUANGAN UMUM (JAKARTA, 2017)
}

\author{
Fanny Amalina, Dr. Matin, M.Pd, Amril Muhammad, S.E.,M.Pd
}

\author{
fannyamalinaa@gmail.com
}

\begin{abstract}
This research was conducted at the General Finance Training Center. Which aims to identify training management Mastering Islamic Finance process. This research was done since october 2016 to january 2017. This research was using a qualitative approach with descriptive methods. Data collection is done through interview, observation and documentation study. Source of research data comes from key informants head of planning and development division, head of implementation division, and several informants supporters such as head of curriculum subdivision, currculum subdivision and implementation subdivision staff.

The results of this study indicate that: (1) Planning of Mastering Islamic Finance Training begins with training need analysis, preparing curriculum, materials, teaching materials, assign teachers, the requirements of the participants, the venue for training. Implementation of Mastering Islamic Finance Training at the general finance training center appropriate with the guidelines. (2) Implementation of the training activities carried out through several stages including methods independent study and face-to-face. The determination of participants Mastering Islamic Finance training based on the recommendation of General of Budget Financing and Risk Management
\end{abstract}

Keywords: Training Management, Mastering Islamic Finance

\section{Pendahuluan}

Ekonomi Islam di Indonesia merupakan sesuatu yang baru, namun memiliki peranan penting dalam perekonomian di Indonesia. Peranan ekonomi Islam dirasakan secara langsung oleh masyarakat, mulai dari pengelolaan uang, asuransi, dan memudahkan masyarakat untuk mengembangkan usaha. Salah satu kegiatan yang dilakukan ekonomi Islam adalah melakukan sistem bagi hasil dengan mengutamakan keadilan dan kesepakatan yang didapat melalui pihak yang bersangkutan, sehingga tidak ada pihak yang merasa dirugikan. Munculnya ekonomi Islam di Indonesia disebabkan oleh perkembangan ekonomi Islam yang terjadi di luar negeri. Oleh sebab itu, ekonomi Islam di Indonesia sekarang ini mengalami perkembangan pesat. Perkembangan ekonomi Islam tidak hanya ditandai dengan munculnya lembaga keuangan syariah, melainkan juga ditandai dengan munculnya berbagai produk di dalam Keuangan Syariah, yaitu memiliki Pasar Modal Syariah, Perbankan Syariah, Asuransi Syariah, dan produk keuangan sukuk. Bahkan munculnya berbagai sertifikasi internasional tentang ekonomi Islam.

Sistem yang digunakan oleh ekonomi Islam berbeda dengan ekonomi konvensional karena ekonomi Islam menganut sistem yang diajarkan oleh syariat Islam berdasarkan pada AlQur'an dan Sunnah yang mampu memberikan keadilan kepada masyarakat. Sedangkan ekonomi 
konvensional lebih bersifat individual. Agar sesuai dengan syariat Islam, dalam melaksanakan kegiatannya ada ruang lingkup ekonomi Islam yang perlu diperhatikan agar segala aktivitas yang dilakukan dalam ekonomi Islam sesuai dengan nilai-nilai Islam. Agar implementasi ekonomi Islam berjalan sesuai rencana dalam mencapai tujuan secara efektif dan efisien, solusinya adalah dibutuhkan pegawai yang berkompeten dalam bidang ekonomi Islam. Di samping itu pegawai yang belum mempunyai kompetensi dalam bidang ekonomi Islam, maka akan dilatih dan dibina oleh suatu lembaga yang memiliki program pelatihan mengenai ekonomi Islam.

Kementerian Keuangan adalah pemilik kewenangan penuh terhadap kegiatan ekonomi Islam yang berada di Indonesia. Direktorat Pembiayaan Syariah di bawah pembinaan Direktorat Jenderal Pengelolaan Pembiayaan dan Risiko sebagai unit Eselon I di bawah kewenangan Kementerian Keuangan Republik Indonesia, bertugas dalam merumuskan serta melaksanakan kebijakan dan standardisasi teknis di bidang pengelolaan pembiayaan dan risiko. Dalam menjalankan tugasnya, Kementerian Keuangan Republik Indonesia memiliki Badan Pendidikan dan Pelatihan Keuangan yang juga merupakan unit Eselon I dan memiliki tugas untuk membimbing serta memberikan pelatihan terhadap pegawai-pegawai yang berada di lingkungan Kementerian Keuangan Republik Indonesia. Tujuannya agar berkualitas, memiliki keahlian, keterampilan bekerja dan pengetahuan yang luas. Diharapkan pelatihan juga dapat membantu pegawai Kementerian Keuangan agar profesional, produktif dan memiliki etos kerja tinggi, sehingga mampu memberikan kontribusi yang berkualitas dan berkuantitas terhadap pelayanan kebutuhan guna melaksanakan tugas dalam pembangunan nasional.

Berdasarkan hasil wawancara yang dilakukan di Pusdiklat Keuangan Umum. Kementerian Keuangan adalah Kementerian yang ada di Indonesia yang menyelenggarakan urusan pemerintahan dibidang keuangan negara untuk membantu Presiden dalam menyelenggarakan pemerintahan di Indonesia dan juga penggerak utama pertumbuhan ekonomi Indonesia. Dengan begitu seharusnya pegawai Kementerian keuangan harus memiliki kompetensi yang lebih karena mereka adalah orang-orang yang mengurusi pengelolaan barang milik kekayaan negara yang menjadi tanggung jawab Kementerian Keuangan di Indonesia. Pusdiklat Keuangan Umum adalah unit organisasi di bawah Badan Pendidikan dan Pelatihan Keuangan yang merupakan unit Eselon II di lingkungan Kementerian Keuangan yang berfungsi sebagai suatu lembaga pelatihan dalam menghasilkan pegawai yang berkualitas melalui penyediaan berbagai program pelatihan yang fokus dan terintegrasi sehingga dapat memberikan kontribusi yang optimal bagi pencapaian tujuan Kementerian Keuangan Republik Indonesia. Sesuai dengan Peraturan Menteri Keuangan Republik Indonesia Nomor 37/PMK.012/2014 bahwa dalam rangka mengembangkan kompetensi sumber daya manusia di lingkungan kementerian keuangan, perlu diselenggarakan pola pendidikan dan pelatihan yang terarah, terstruktur dan berkesinambungan sesuai dengan dinamika kebutuhan seluruh unit di lingkungan kementerian keuangan. Berdasarkan pengamatan di lapangan dan karena adanya keterbatasan peneliti, maka peneliti tertarik untuk melihat dan menganalisis Manajemen Pelatihan Mastering Islamic Finance yang ada di Pusdiklat Keuangan Umum. dengan subfokus yang meliputi perencanaan dan 
pelaksnaan Pelatihan Mastering Islamic Finance.

\section{Tinjauan Pustaka}

Menurut Monappa dan Saiyadain (2006:175), "training refers to the teaching/learning activities carried on for the primary purpose of helping members of an organization to acquire and apply the knowledge, skills, abilities and attitudes needed by that organization." Menurut Wilson yang dikutip oleh Kaswan (2015:204), " $a$ planned process to modify attitude, knowledge or skill behaviour through learning experience to achieve effective performance in an activity or range of activities. Its purpose, in the work situation, is to develop the abilities of the individual and to satisfy the current and future needs of the organization." Lucas (2010:195) menyatakan bahwa, "training is an intrinsic part of the organizational development process."

Menurut Dessler (2015:643), "training is the process of teaching new or current employees the basic skills they need to perform their jobs. "Kamsir (2016:126) menyatakan bahwa pelatihan merupakan proses untuk membentuk dan membekali karyawan dengan menambah keahlian, kemampuan, pengetahuan dan perilakunya.

Menurut Davies yang dikutip oleh Daryanto dan Bintoro (2014:116) manajemen pelatihan sebagai suatu proses, istilah manajemen atau pengelolaan pelatihan berdampingan dengan trisula aktivitas, yakni a) perencanaan, b) pelaksanaan, dan c) evaluasi. Menurut Laird, Naquin, and Holton (2003:221), "management doesn't care about test results. they care about the results employees achieve by using their training: that's the only way to "sell" training to management"

Menurut Seigel dan Shim yang dikutip oleh Fahmi (2014:19) menyatakan bahwa perencanaan adalah pemilihan tujuan jangka pendek dan jangka panjang serta merencanakan taktik dan strategi untuk mencapai tujuan tersebut. Chaturvedi (2013:45) menyatakan bahwa perencanaan yaitu, "planning is the most fundamental and the most pervasive of all management functions." Menurut Arifin dan Muhammad (2016:3) menyatakan bahwa perencanaan adalah suatu proses yang terpenting dari semua fungsi manajemen karena tanpa perencanaan, fungsi-fungsi lainnya tidak akan berjalan. Amirullah (2015:62) menyatakan bahwa perencanaan yaitu pemilihan saat ini terhadap masa depan yang kita kehendaki (choosing our desired future today) beserta langkahlangkah yang kita perlukan untuk mewujudkan kondisi-kondisi tersebut. Menurut Robbins dan Coulter yang dikutip oleh Silalahi (2015:149) menyatakan bahwa, "planning involves defining the organizational's goals, establishing an overall strategy for achieving those goals, and developing a comprehensive set a plans to integrate and coordinate organizational work."

Menurut Hidayat dan Tjitrosoemarto (2015:45) menyatakan bahwa perencanaan merupakan penyusunan langkah-langkah kegiatan yang akan dilaksanaka berdasarkan jangka waktu tertentu yaitu, jangka panjang, jangka menengah dan jangka pendek. Menurut Hamalik (2007:79) menyatakan bahwa pelaksanaan pelatihan perlu memperhatikan 4 tahapan pelaksanaan pelatihan, yang terdiri dari tahap pendahuluan, pengembangan, kulminasi, dan tindak lanjut.

\section{Metode Penelitian}

Pendekatan yang di gunakan dalam penelitian adalah pendekatan kualitatif dengan metode deskriptif. Penelitian ini dilakukan di Pusdiklat Keuangan Umum yang berlokasi di 
Jalan Pancoran Timur II No. 1, Jakarta Selatan. Penelitian dilakukan selama kurang lebih empat bulan. Pengumpulan data dilakukan melalui wawancara, observasi, dan studi dokumentasi. Tahapan penelitian yang dilakukan terdiri dari tahap tahap pra lapangan, tahap pekerjaan lapangan dan tahap analisis data. Tahap pra lapangan meliputi menyusun rancangan penelitian, memiih lapangan penelitian, mengurus perizinan, menajajaki dan menilai keadaan lapangan, memilih dan memanfaatkan informan. Selanjutnya tahapan pekerjaan lapangan yang meliputi memahami latar penelitian dan persiapan diri, memasuki lapangan dan mengumpulkan data informasi dari penelitian. Tahap analisis data terdiri dari proses reduksi data, klasifikasi data, penyajian data, dan verifikasi data atau menarik kesimpulan.

\section{Hasil dan Pembahasan}

Perencanaan pelatihan Mastering Islamic Finance di Pusdiklat Keuangan Umum melibatkan unit Direktorat Pembiayaan Syariah Direktorat Jenderal Pengelolaan Pembiayaan dan Risiko (DPS DJPPR). Selain itu juga melibatkan Narasumber, dan Pegawai Pusdiklat Keuangan Umum yang ikut membantu dalam perencanaan pelatihan Mastering Islamic Finance. Dengan begitu pusdiklat keuangan umum saling koordinasi dengan unit Direktorat Pembiayaan Syariah Direktorat Jenderal Pengelolaan Pembiayaan dan Risiko (DPS DJPPR). Pelaksanaan perencanaan pelatihan Mastering Islamic Finance dilakukan pada triwulan satu. Perencanaan pelatihan Mastering Islamic Finance dilakukan dengan beberapa tahapan yang diawali dengan training need analysis pada saat customer voice. Analisis kebutuhan pelatihan ini merupakan kegiatan yang dilakukan untuk menganalisis pelatihan apa yang diperlukan oleh lingkungan Kementerian Keuangan. Cara analisis kebutuhan pelatihan Mastering Islamic Finance diawali dari customer voice dalam Learning Needs Diagnosis, caranya yaitu pusdiklat keuangan umum melakukan koordinasi dengan DPS DJPPR dan melakukan perencanaan mulai dari peserta, tenaga pengajar, dan program pelatihan.

Dalam proses perencanaan pelatihan Mastering Islamic Finance diawali dengan pihak pusdiklat keuangan umum membuat nota dinas yang berisi pemberitahuan tentang pertemuan formal untuk melakukan analisis kebutuhan pelatihan Mastering Islamic Finance secara rinci. Setelah nota dinas disampaikan ke DPS DJPPR. Selanjutnya, unit DPS DJPPR mengusulkan pegawai mereka yang ingin mengikuti pelatihan Mastering Islamic Finance dan mengirimkan surat usulan tentang peserta yang ingin mengikuti pelatihan Mastering Islamic Finance ke pusdiklat keuangan umum. Tahap selanjutnya adalah Design and Develop, yaitu diadakan rapat koordinasi mengenai pelatihan Mastering Islamic Finance yang membahas penyusunan konsep design kurikulum, pembahasan metode yang digunakan, bahan ajar, materi, mengatur jadwal kegiatan pelaksanaan pelatihan Mastering Islamic Finance. Selanjutnya persyaratan peserta dan kualifikasi tenaga pengajar pelatihan Mastering Islamic Finance.

Setelah penyusunan kurikulum, penetapan keputusan tenaga pengajar dan data dari calon peserta sudah masuk, selanjutnya adalah konfirmasi kesesuaian kurikulum ke unit DPS DJPPR. Tahap selanjutnya adalah Deliver and Deployment, yaitu rapat persiapan dan tahap dimana penyelenggaraan pelatihan Mastering Islamic Finance dimulai. Dalam pelaksanaan rapat ini dapat membantu pegawai yang bertanggung jawab atas pelatihan Mastering Islamic Finance 
yang disebut Person In Charge (PIC) agar mengetahui secara teknis proses metode pembelajaran pelatihan Mastering Islamic Finance menggunakan aplikasi Knowledge Management. Rapat persiapan pelatihan Mastering Islamic Finance dilakukan dengan tenaga pengajar, pusdiklat keuangan umum dan DPS DJPPR. Tahap pelaksanaan pelatihan Mastering Islamic Finance ini berisi kegiatan yang dilaksanakan dalam pelatihan. Termasuk didalamnya kegiatan belajar mengajar tatap muka dikelas maupun di Independent Study. Tahapan proses pelaksanaan pelatihan Mastering Islamic Finance adalah diawali dengan pemanggilan peserta pelatihan Mastering Islamic Finance yang dilakukan dengan cara pemberitahuan melalui website aplikasi knowledge management oleh bidang penyelenggaraan pusdiklat keuangan umum, pelatihan Mastering Islamic Finance memang dianjurkan untuk selalu mangakses website karena infor di website selalu uptodate. Setelah pemanggilan peserta pelatihan Mastering Islamic Finance dilakukan tahap selanjutnya yaitu pemberitahuan kewajiban pelatihan Mastering Islamic Finance diberitahu untuk mengikuti tata tertib yang berlaku, mengikuti rangkaian pelatihan sesuai dengan waktu yang ditentukan, hadir lima belas menit sebelum pelatihan dimulai dan berpakaian rapih sesuai ketentuan Kementerian Keuangan serta menggunakan nametag. Tahap selanjutnya yaitu pelaksanaan pelatihan Mastering Islamic Finance. Proses pelaksanaan pelatihan Mastering Islamic Finance dilaksanakan di Ruang Aula Lantai 1 Pusdiklat Keuangan Umum. Pelaksanaan pelatihan Mastering Islamic Finance terdiri dari dua metode diantaranya metode independent study dan tatap muka. Jumlah peserta pelatihan Mastering Islamic Finance 30 orang. Kegiatan pelatihan Mastering
Islamic Finance dilakukan selama sepuluh hari dan dilakukan dalam kurun waktu dua minggu, yaitu lima hari setiap satu minggu. Tahap awal pelaksanaan pelatihan Mastering Islamic Finance menggunakan metode off the job training dalam bentuk independent study.

Pada tahap independent study peserta akan dipersiapkan dengan pemberian tugas melalui aplikasi knowledge management system dan gambaran secara umum terkait pelaksanaan tatap muka. Selanjutnya yaitu tatap muka, tahap ini adalah waktunya pengumpulan tugas yang sudah diberikan melalui website. Metode pembelajaran di dalam kelas yang digunakan adalah simulation yaitu peserta menciptakan kondisi belajar yang sangat sesuai atau mirip dengan kondisi pekerjaan. Pada tahap tatap muka peserta akan diberikan simulasi pada setiap harinya. Simulasi dilakukan dua sampai tiga kali dalam satu hari pelaksnaaan pelatihan Mastering Islamic Finance. Kegiatan yang dilakukan peserta pelatihan pada tahap tatap muka adalah peserta mempelajari mengenai keuangan Islam agar dapat menyusun dan merancang konsep instrumen keuangan syariah. Setiap harinya peserta mempelajari lima hingga enam materi pelajaran.

Fasilitas yang diperoleh peserta selama pelatihan yaitu: perpustakan, poliklinik, ruang laktasi, masjid, ruang makan, kantin dan mini market, pojok informasi, hotspot, toilet, dan lapangan parkir. Sedangkan fasilitas pelatihan pelatihan Mastering Islamic Finance yang disediakan di dalam kelas seperti: konsumsi meliputi dua kali snack yang diberikan pada saat coffee break dan makan siang, buku panduan pelaksanaan pelatihan Mastering Islamic Finance, modul atau bahan ajar, tas beserta alat tulis, dan ruang kelas full AC. Setelah pelaksanaan pelatihan Mastering Islamic Finance tatap muka selesai dilaksanakan 
tahap selanjutnya yaitu mengikuti Post Test. Hasil Post Test dimaksudkan untuk menguji dan menilai sejauh mana pengetahuan dan kemampuan pelatihan Mastering Islamic Finance selama mengikuti pelaksanaan pelatihan.

\section{Kesimpulan dan Implikasi}

Perencanaan
Mastering Islamic Finance dilakukan
oleh Pusdiklat Keuangan Umum dan
bekerjasama dengan unit Direktorat
Pembiayaan Syariah Direktorat Jenderal
Pengelolaan Pembiayaan dan Risiko
diawali dengan dengan training need
analysis pada saat customer voice.
Setelah melakukan analisis kebutuhan
pelatihan, selanjutnya pusdiklat
keuangan umum melakukan
perencanaan program pelatihan Mastering Islamic Finance, dengan melakukan pertemuan formal untuk membahas kebutuhan pelatihan lebih rinci. Selanjutnya pusdiklat keuangan umum menerima usulan peserta pelatihan Mastering Islamic Finance dari unit Direktorat Pembiayaan Syariah Direktorat Jenderal Pengelolaan Pembiayaan dan Risiko. Kemudian setelah proses pertemuan Direktorat Pembiayaan Syariah Direktorat Jenderal Pengelolaan Pembiayaan dan Risiko dengan pusdiklat keuangan umum berjalan, kegiatan diserahkan kepada bidang perencanan dan pengembangan diklat sebagai bidang yang melakukan penetapan kalender pelaksanaan pelatihan Mastering Islamic Finance dan mendesain kurikulum. Penetapan kalender pelatihan dilakukan oleh subbid program, sedangkan pembuatan kurikulum dilakukan oleh subbid kurikulum, mulai dari bahan ajar, membuat materi pelajaran, jadwal kegiatan pelatihan, metode pelatihan yang menggunakan dua metode yaitu independent study dengan menggunakan aplikasi knowledge management dan tatap muka yang dilakukan di dalam gedung pusdiklat keuangan umum, hingga menetapkan tenaga pengajar.

Dalam melakukan perencanaan program pelatihan Mastering Islamic Finance, pusdiklat keuangan umum melakukan koordinasi dengan Direktorat Pembiayaan Syariah Direktorat Jenderal Pengelolaan Pembiayaan dan Risiko untuk mambahas dan merumuskan tujuan, kurikulum, materi, metode yang tepat untuk pelatihan Mastering Islamic Finance yang disesuaikan dengan konsep coorporate university serta melibatkan para pranata komputer dan widyaiswara dalam menggunakan knowledge management system. Melalui rapat koordinasi disampaikan terkait dengan knowledge management system akan diisi dengan kurikulum dan materi kuis-kuis sebagai media pembelajaran peserta pelatihan dan bagian TIK siap untuk memfasilitasi kebutuhan di unit pusdiklat keuangan umum terkait dengan kebutuhan penggunaan aplikasi knowlegde management system. Kemudian selanjutnya melakukan konfirmasi kesesuaian kurikulum, apabila konsep kurikulum disetujui, tahap selanjutnya yaitu pelaksanaan pelatihan.

Pelaksanaan pelatihan

Mastering Islamic Finance oleh Pusdiklat Keuangan Umum diawali dengan pelaksanaan sesi independent study selama lima hari dengan diberikan materi yang di uploud di knowlegde management system dan diberikan tugas di aplikasi knowlegde management system. Tahapan selanjutnya yaitu pelaksanaan sesi tatap muka yang dilaksanakan di gedung pusdiklat keuangan umum dan selama tatap muka melaksanakan dua belas kali simulasi dan pembahasan materi. Selanjutnya yaitu melaksanakan proses pre test dan mengumpulkan tugas yang diberikan pada saat independent study. Setelah melakukan rangaian kegiatan pelaksanaan pelatihan Mastering Islamic Finance, selanjutnya pada pertemuan 
sesi tatap muka di hari akhir itu diadakan post test, yang dilakukan sebelum mata pelajaran terakhir. Kegiatan ini diselenggarakan untuk mengukur atas peningkatan pengetahuan peserta pelatihan Mastering Islamic Finance. Kegiatan pelaksanaan pre dan post test peserta pelatihan Mastering Islamic Finance dirancang menyerupai ujian sertifikasi Islamic Finance Qualification (IFQ).

\section{Saran}

1. Bagi Kepala Pusdiklat Keuangan Umum Kepala Pusdiklat perlu mempertahankan hal-hal positif dalam pelatihan Mastering Islamic Finance. Rapat review kurikulum yang dijalankan pusdiklat harus dipertahankan karena dengan begitu program pelatihan yang dijalankan sesuai dengan perkembangan zaman. Selain itu juga pusdiklat keuangan umum sebaiknya memiliki tenaga pranata komputer sendiri yang ahli di bidangnya, agar pusdiklat tidak bergantung kepada pejabat TIK BPPK. Pusdiklat keuangan umum sebaiknya juga memberdayakan pihak internal pusdiklat untuk melakukan sosialisasi, publikasi mengenai knowledge management system yang belum familiar. Pusdiklat keuangan umum juga sebaiknya menambah koleksi buku di perpustakaan, agar mendukung dalam menyediakan ilmu agar dapat mengembangkan potensi pegawai dalam menghasilkan kinerja yang lebih baik.

2. Bagi Pegawai Pusdiklat Keuangan Umum

Pegawai pusdiklat harus tetap menajaga kerja sama, hal ini demi mendukung pelaksanaan tugas agar lebih optimal dan dapat mengatasi segala hambatan bersama. Pegawai pusdiklat juga harus meningkatkan inovasi dalam membuat program pelatihan.

3. Bagi Peneliti Lain

Penelitian selanjutnya diharapkan dapat menyiapkan diri dalam proses pegambilan serta pengumpulan data dan diharapkan juga untuk mendapatkan lebih banyak sumber referensi yang terkait dengan manajemen pelatihan keuangan Islam agar hasil penelitiannya dapat lebih lengkap lagi.

\section{Daftar Pustaka}

Amirullah. (2015). Pengantar Manajemen Fungsi, Proses, Pengendalian. Jakarta: Mitra Wacana Media

Arifin, Rois dan Helmi Muhammad. (2016). Pengantar Manajemen. Malang: Empatdua

Chaturvedi, Rachna. (2013). Managing Organizations. New Delhi: Vikas Publishing

Daryanto dan Bintoro. (2014). Manajemen Diklat. Yogyakarta: Gava Media

Dessler, Gary. (2015). Human Resource Management. New jersey: Pearson Education

Fahmi, Irham. (2014). Manajemen Teori, Kasus, dan Solusi. Bandung: Alfabeta

Hamalik, Oemar. (2007). Pengembangan Sumber Daya Manusia Manajemen Pelatihan Ketenagakerjaan. Jakarta: Bumi Aksara

Kasmir. (2016). Manajemen Sumber Daya Manusia (Teori dan Praktik). Jakarta: Rajawali Pers

Kaswan. (2015). Pengembangan Sumber Daya Manusia. Bandung: Alfabeta

Laird, Dugan, Sharon S. Naquin, Elwood F.Holton. (2003). Approaches to Training and Development. New York: Basic Books 
Lucas, Robert W. (2010). Energize Your Training: Creative Techniques to Engage Learners. East Peoria: ASTD Press

Monappa, Arun dan Mirza Saiyadain. (2015). Personnel Management. New Delhi: Tata McGraw-Hill Publishing
Mujiman, Haris. (2009). Manajemen Pelatihan Berbasis Belajar Mandiri. Yogyakarta: Pustaka Pelajar

Silalahi, Ulber. (2015). Asas-Asas Manajemen. Bandung: PT. Refika Aditama 